\title{
Politics and Politicking: The Organizational Perspective
}

\author{
Emmanuel O. Adu PhD \\ Faculty of Education, University of Fort Hare, East London, South Africa \\ eadu@ufh.ac.za \\ Gbadegesin M. Akinloye \\ Department of Educational Management, Faculty of Education, University of Ibadan, Nigeria \\ gbadegesinakinloye@yahoo.co.uk \\ Olabisi F. Olaoye \\ Faculty of Education, University of Fort Hare, East London, South Africa \\ olabisiolaoye@yahoo.com
}

\section{Doi:10.5901/mjss.2014.v5n20p1051}

\section{Abstract}

The totality of our community, society, the whole world and even the entire universe is an organization. Organizing involves developing a structure of roles for effective performance and it requires a network of decision and communication for coordinating efforts towards group and enterprise goals. For effectiveness an organizational structure must be understood and principles and policies must be put into practice through the structural organizational politics. Power and politics are interrelated and interwoven with the fabric of an organization. Politics, power and politicizing are necessary, unavoidable and inevitable. The paper therefore examined the features of organizational structure, sources of power, leadership styles, features and tactics of organizational politics. The paper equally examined the mistakes in organizational setting and way out. It was then concluded that effective managers need to be fully aware of the existence of political tactics, have the required wisdom, knowledge, skill and should learn how best to manage the organizational politics for the efficacy of the organizational setting.

Keywords: Scapegoating, Political Tactics, Power, Politicking, Dysfunctional Politicking, Organizational Politics and Politician.

\section{Introduction}

Ordinarily, the word 'politics' tends to connote the campaign strategies of humans to win votes, the game people play to win power, the methods and tactics involved in managing the control of human organizations. People often talk of mosque/ church / shrine politics; office politics and village politics, politics of student unionism, family politics, politics of consensus and the partisan or fractional intrigue within the given organization. Every human organization has its politics, power struggle and influence wielding. A political scientist defines politic as "who gets what, when, where, and how", and another regards politics as the struggle for power to name the personnel who determines the policies of government. Owolabi (2007) defines politics as a process through which any group selects, distributes its advantages and disadvantages. He also defined politics as the process through which the authoritative allocation of values takes place. Ejiogu (2005) defined politics as the study of influence and the influential, the influential being those who get, most of what there is to get. Organizational politics are plans, tactics and strategies for seizing, holding, acting and exciting power in organization. Politics are used by individuals and groups to achieve their respective goals.

All organization whether business, educational, religious, political are subject to conflict and rigorous competition between the desires and interests of different departments, teams and individuals. Organizational politics according to Kinicki (2008) could be seen as the process through which these rival interests are played out and eventually reconciled. Although, members of an organization are expected to cooperate in spite of the diverse interests to achieve a commonest goal and competing for rewards and at times, their personal interests may be at odds with the organizational objectives. Mitchell (2005) defined organizational politics as informal approaches to gaining power through means other than merit or luck. Organizational politics are used to gain power either directly or indirectly by promotion to the next level, receiving a larger budget or gaining rewarding assignment. 
The totality of our community, society and the entire world and even the entire universe is an organization. Each one of us is borne into an organization, manufactured in organization, educated by organizations and spends most of our lives working for organizations. Adeyemo, et al (2011) buttressed that our leisure is spent in playing, praying and worshipping in organizations. Organization according to Adeyemo et al (2011) can be perceived as the most potent social grouping for coordinating a large number of human actions, all the available resources are mobilized to achieve set goals.

Adeyemo et al (2011) define organization as social units or human groupings deliberately constructed to seek specific goals. These include corporations, armies, schools, hospitals, churches, mosques, prisons etc. Ojo (2012) defines an organization as a group of people bound together in a formal relationship to achieve organizational goal. Symbolic interpretation sees organization as continually constructed and reconstructed by their members through symbolically mediated interaction. Organization could also be described as the embodiment of unity and common purpose because workers in the organization assist to achieve plans agreed upon by all. Ojo (2012) defined organization as a social economic entity in which a number of individuals perform a variety of tasks in order to reach a common objective. The objective is typically too large or too complex for a single person cutting alone to accomplish.

Organizational structure comprises of functions, relationships, responsibilities, authorities and communications of individuals within each department. It is the structure that determines the hierarchy and the reporting structures in the organizational chart structure is the basic framework within which the executive's decision making behavior takes place. The organizational structure can take the form of any of the following types according to Ojo (2012).

\subsection{Normative Culture}

The norms and procedures within the organizations are predefined and the rules and regulation are set as per the existing guidelines. The employees of the organization behave in an ideal way and comply with the policies of the organization.

\subsection{Pragmatic Culture}

Here, emphasis is placed on the clients and the external parties. The main motive of the employees is customers' satisfaction. In such an organization, customers are treated as kings and queens and they do not follow any set rules. Every employee strives to satisfy the customer to expect maximum business from their side.

\subsection{Academic Culture}

Skilled individuals are recruited. The roles and responsibilities are delegated according to the background, educational qualification and job experience of the employees. Here the training and retraining are important and the management makes genuine efforts to upgrade the knowledge of employees in an academic political culture and to stick to the organization for a larger duration to grow within it.

\subsection{Basket team culture}

This culture considers the employees as the most treasure possession of the organization. The employees are the true assets of the organization who have a major role in its successful functioning. The individual employees always have an upper edge and they do not bother much about their organization. Examples of these types of organizations include companies, financial institutions, advertising agencies etc.

\subsection{Club Culture}

The individual is recruited as per their specialization, educational qualification and interest. Each individual does what he is best at. The high potential employees are suitably promoted and their appraisals are regular.

\subsection{Fortress culture}

This is a type of organization where employees are not very sure about their career and longevity. They follow fortress culture and the employees are terminated if the organization is not performing well. Individuals suffer when the organization is at loss. Example of this type of organization is stock broking. 


\subsection{Tough Guy Culture}

Feedbacks are essential in a tough guy culture. The performance of the individual employees is reviewed from time to time and their work is thoroughly monitored. Team managers are appointed to discuss issues with the team members and guide them whenever required. The employees are under constant watch and monitoring.

\subsection{Bet Your Company Culture}

These types of organizational culture take decisions which involve a huge amount of risk and the consequences are also unforeseen. The principles and policies of such organization are formulated to address sensitive issues and it takes time to get the results.

\subsection{Progress Culture}

The employees in this type of culture adhere to the process and procedures of the organization. Feedbacks and performance reviews do not matter much here. The employees abide by the rules and regulations and work according to the ideologies of the workplace.

\section{Sources of Power in Organization}

The concepts of authority and power are very germane to organizational structure of any type. This is because power and authority form the basis and instrument of control over the behavior of subordinates on an organization to ensure that the goals of an organization are achieved. Authority could be defined as the formal right to exercise control over subordinates, the right being conferred by virtue of one's position in the organization. Authority is very essential to control work and achieve organizational objectives. Power is the ability or capacity to exercise control over others at times against their own will. There are five different types of or sources of power exist in an organization. They are:

\subsection{Reward power/Remunerative/Resource power}

It exists when one person offers rewards to another person in exchange for desired behavior. The reward could be in form of money, material, praise, promotion and recognition. For the reward power to be effective in achieving the desired result, the individual or group being offered must actually value the reward. The value system varies with people depending on situations, needs and status.

\subsection{Coercive Power}

This is the use of punishment or threat of it. The punishment may be physical or non-physical. Physical coercion is applied in prisons and mental homes while non-physical punishment involves the denial of financial or non-financial privileges or the use of dismissal from the organization.

\subsection{Legitimate or positional power}

The power here is derived from the position of a person in an organization. This power is based on the belief that the person exercising control has the right to do so. Legitimate power is the same as authority which is accepted or acknowledged by those over whom it is exercised.

\subsection{Referent power}

This is the ability to exercise control by sheer force of personality or charisma. It does not derive from the ability to offer reward or to inflict punishment or by virtue of a person's position in the organization.

\subsection{Expert power}

This is the ability to control others as a result of one's actual or claimed knowledge or expertise in a given filed. The 
expertise that a person possesses or claim to possess must be acknowledged by those over whom the power is to be exercised so that they may submit willingly to it.

Different types of power create different effects and responses from individual members of the organization. The first type of response or involvement is called 'calculative involvement' which is generated by the use of reward or remunerative power. It is an economic instrumental involvement whereby legislative or position power is likely to ensure full and whereby an individual participates voluntarily in an organization - the benefits which he expects to get from his membership of the organization. Membership of an organization is the result of a rational decision which they may decide to stay or leave the organization depending on the remuneration or benefits of the organization to them. The second response or involvement is called 'moral involvement' which results from the use of normative power which is the power or ability to exercise control by allocating or withholding symbolic rewards such as prestige or acceptance. This is committed and strongly favorable form of involvement or identification with an organization and its goals and mission. (Examples of this are found among members of religious and political groups where membership is maintained because of commitment to certain ideals which the organization stands for.

The third involvement revolves round alternative involvements which result from the use of coercive power which is manifested as threat and punishment. It is a state of non- identification with the organizational goals. It is a negative form involvement in which individuals strongly oppose or dissociate themselves from the organization. Membership of the organization is involuntary since it is against their will. Examples of this are typical of prison inmates, patients of mental homes where they are forced to secure compliance.

According to Ajayi (2009), the success of an organization is dependent upon many factors, but none is as important as the import of its leaders at different levels. Leadership in any organizational setting whether, educational, economic, political, at different levels makes decision that consequently determines the purpose, goals and means of fulfilling them. Leadership is very sensitive for organizational survival or failure; the leaders is always commended for the success and reprimanded or blamed for any form of failure or lapses. Adeyemi et al. (2011) in his study of the organization claimed that when things go wrong in the organization, it should be blamed on the leader rather than the organizational members

Chike-Okoli (2009) defines leadership as a person or ability to lead group of people in an organization for the attainment of an objective. Leadership could also be seen as a process influencing the activities of an organized group towards goal setting and goal achievement. Ojo (2012) sees leadership as a process in which an executive or a manager imaginatively directs, guides and influences the work of other in choosing and attaining specified goals by mediating between the individual and the organization in such a manner that both will obtain the maximum satisfaction. Ojo (2012) sees leadership as a social influence process in an effort to reach organizational objectives. The definitions of leadership are as many and varied as there are different human beings. However, the main theme of leadership is getting things accomplished through people. It can then be deduced according to Chike-Okoli (2009) that leadership involves the achievement of an organizations goal through a process of influencing, directing, acquiring nominative personal characteristics and power and coordinating group activities to make individuals in the organization strive willingly towards, the attainment of the organizational set goals or solution to a mutual problem. It is then generally agreed that the quality of leadership in an organization be, it religious, social economic educational, military, cultural or otherwise affects to a very large extent, the success or failure of the organization.

Chike-Okoli (2009) identified four aspects of leadership definition which are:

- Its substance: what workers have to do?

- It process: how they accomplish it?

- Its purpose: the ways and reasons for leadership.

- What leaders will have to do? In leadership, employees can be motivated by one or more of the following:

- Job security, enrichment and satisfaction

- Provision of good working environment

- Provision of recreational facilities such as different types of games.

- Promotion and salary increase as at when due.

- Children education as one of the methods of encouraging and retraining employees in any organization. It is a form of support for employees.

- Study leave with or without pay.

- Fringe benefits such as luncheon vouchers, coupons, transport facilities, leave bonuses etc.

- Understanding subordinates and their goals are meeting their needs.

Base on the leadership conceptualization in an organization. Chike-Okoli (2006) develops the managerial grid from which 
they identify five leadership styles as:

\subsection{Impoverished leadership}

This style makes minimum effort to get required work done and enough concern for people is made to sustain organizational membership. The leadership simply passes information from above to the subordinates and has little or no influence over his subordinates.

\subsection{Task-oriented leadership}

Emphasis is placed on work while good relation is incidental. Production is the main concern. So close supervisions and authoritarian style is noticed and interaction is strictly official.

\subsection{People-oriented leadership}

This leadership style focuses on the need of the people and production is incidental. The leadership place more emphasizes on sound interpersonal relation and keep organization goals ambiguously or general so as make room for the personal needs of the members, which is contrary to organizational goals. Leaders make effort to avoid conflict and develop a high moral among members.

\subsection{Balanced leadership}

This style of leadership is to achieve equilibrium by striking a balance high productivity and good relation in an organization to ensure that neither the needs nor goals of the organization are neglected.

\subsection{Integrated leadership}

This leadership style shows a high concern for both production and people, when a leadership style is balanced, work is accomplished by highly committed motivated people and effort is made to achieve high degree of congruence between organizational goals and the personal goals and the personal goal of member. Communication is free to aid team work and group decision-making.

Chike-Okoli (2009) described another set of five leadership styles as:

\subsection{Autocratic or Authoritarian leadership style}

The "tells" rather than 'sells' or "consults'. It is a one man show and does not motivate the subordinates.

\subsection{Bureaucratic leadership style}

The leadership sticks to fix rule-a hierarchy of authority and narrow, rig it, formal routines.

\subsection{Diplomatic leadership style}

The interest of leaders lies in working with people when solving an identified problem. He "sells" rather 'tells'. He motivates and gains co-operation of his staff.

\subsection{Participatory leadership style}

This leadership style allows the employees and executives to take decision together. The super ordinate executives allow the subordinates to know that they are accountable and thus have the right to make the final decision. The involvement of the staff in decision making process helps to obtain good information and ideas. 


\subsection{Free-rein or lasses-faire leadership style}

The leader sets the goals and develops guidelines for the subordinates who now act without further direction from the leader.

\section{Political Behavior in Organizations}

According to Mitchel (2005) organizational politics are as a result of the fact that people think and act differently and these create tension that must be resolved through organizational politics. This can be done autocratically "we will" do it this way, bureaucratically, "we are supposed to do it this way"; technocratically, "it is best to do it this"; democratically, "How shall we do it". According to Mitchell (2005), several individuals and organizational factors contribute to political behavior in an organization and some of them are:

\subsection{Pyramid Shaped Organizational Structure}

This structure concentrates power at the top to the extent that each successive layer on the organizational chart has less power than the layer above. At the bottom of the organization, workers have virtually no power. Therefore, the fewer the layers the more intense the competition for power.

\subsection{Subjective Standards of Performance}

Subjectively at times, people resent to organizational politics because they do not believe the organization has an objective way of evaluating their performance and suitability for promotion. In the absence of objectivity on the part of management, then, they will resort to favoritism.

\subsection{Environmental Uncertainty and Turbulence}

In an unstable and unpredictable environment, people seem to behave politically and tend to rely on organizational politics to create favorable impression because uncertainty makes it difficult to determine what they should really be accomplishing. Uncertainty, turbulence and insecurity created by mergers or downsizing is a major contributor to organizational politics.

\subsection{Emotional Insecurity}

Some people tend to resort to political maneuvering to ingratiate themselves with super ordinates because they lack confidence in their talents and skills.

\subsection{Manipulative Tendencies}

Some people tend to engage in politics because they want to manipulate others for their own personal advantage.

\subsection{Disagreements}

Rational decision making is at times constrained by major agreement over what the organization should be doing. Except strategy and goals are shared strongly among key organizational members, political motivation is inevitable in organizational decision making.

\section{Political Strategies and Tactics}

For organizational politics to be effective, organizational leaders must make appropriate use of specific political strategies and tactics. Ethical behavior should be considered as an important requirement for effective leadership. Mitchell (2005) buttressed that the organizational managers should seek answers to these questions before they engage in a particular influence act or political tactic:

- Is it right? This is based on absolute principle of justice. 
- Is it fair? - This is equally based on the absolute principles of justice.

- Who gets hurt? - This is based on the principles of the fewer the better

- What of if the decisions are made public through the mass media? - This is based on the principle of disclosure

- What would you tell your relatives? This is based on the principle of reversibility.

- How does it smell? - This is based on the principle of common sense and intuition.

\section{Ethical Political Strategies and Tactics.}

The following are the classification of ethical political strategies and tactics;

\subsection{Strategies and Tactics Aimed Directly at Gaining Power.}

All political power and tactics are aimed at acquiring and maintaining power and some of the related tactics include:

1. Power Contacts and Relationship: When powerful people have been identified, alliances are established; cultivating friendly cooperative relationships with powerful organizational members and outsiders can make the leader's course much easier to advance. These contacts can benefit a person by supporting his / her ideas in meeting and other public fora.

2. Early Showing: A display of timely results could help a staff gain acceptance for his/her efforts. Once the positive impression has been created with the ability to solve an important problem, the staff can look forward to working on problems that will bring greater power.

3. Keep Informed: It is politically essential to keep informed and successful organizational managers develop a network to help them keep abreast of developments both within and outside their organization.

4. Control Vital Information: Power accrues to people who have control of vital information. The vital information they control is knowledge of whom to contact to shorten some of the complex and complicated procedures in getting governmental and corporate contracts approved.

5. Control Lines of Communication: these borders mainly on access to key people. Administrative and staff assistants frequently control an executive calendar. Both insiders and outsiders must carry favor with the conduit in order to see an important executive.

\subsection{Strategies and Tactics Aimed at Building Relationships.}

This involves building positive relationship with network members such as superiors / super ordinates, subordinates, other lower - ranking people, coworkers, external customers and supervisors who can be of help now or later. Relationship strategies and tactics can take any of the following forms.

1. Provide Favor and Develop Ingratiation: An intelligent and skilful organizational leader has a positive balance of favors given and could draw on that balance when something is needed in return.

2. Display Loyalty: A loyal worker is valued because an organization prospers more with loyal than disloyal staff. Blind loyalty (organization cannot make mistake) is not needed, for most rational organizations are not all imperious to criticisms instead welcome constructive criticisms.

3. Develop Reputation as a Subject Matter Expert: Expert is one of the major sources of power. Others come to and ask for help from an expert who is an authority over an issue.

4. Rational Persecution: This form of influence helps to create an impression that one is reasonable and fair and it avoids creating resentment that can result from heavy handed influence tactics.

5. Manage Impression of You: Management of impression includes behavior directed at enhancing one's image by drawing positive attention to one's self via clothing, grooming, speaking well and presenting one's ideas coherently.

6. Bring in Outside Experts for Support - Executives will often hire a consultant or a resource person to conduct a study or cost an opinion through regular seminars. This tactic would be considered unethical if the executive is intentionally seeking a non - objective opinion through seminars / resource person.

7. Consult with and Ask Advice of Others: Seeking for advice even when not needed helps to support for a decision. Consultation on work - related topics builds good relationships with other staffs and it will be perceived as a compliment. 
8. Ask Satisfied Customer to Contact your Boss - Favorable comments from customers receive considerable weight because customers' satisfaction is a top priority of any organization. Good comments from customers' satisfaction will carry more weight than one from a coworker or subordinate.

9. Be Courteous, Pleasant, Positive and Friendly: It is a common belief that courteous, pleasant, positive and friendly people with other important qualifications are the first to be hired and the last to be fired.

10. Send Thank - You Notes to Large Numbers of People: Sending thank - you note profusely, is an application of sound human relation. It is an excellent political tactics in an organization. 'Thank you' 'Sorry' and 'Please should' not be too difficult for an organizational leader and should be appropriately used. Successful people send notes to employees and customers on their birthdays and popular festivals to create a bend with those people.

11. Flatter others sensibly and reasonably: Sincere flattery through specific praise could be an effective relationship builder. Also by being generous on feedback and comments, relationship with workers could be built and make them more receptive to the organizational policies.

12. Develop Coalitions: Whether formal or informal, confined to the organization or extended to include key interest or stakeholders outsides, coalition and interest group often provide important means of securing desired ends. Coalition could be initiated by less powerful who seek the support of others. Coalition could as well be developed by the powerful to consolidate their power.

\subsection{Avoiding Political Blunders: These borders on the ability to refrain from making power-eroding blunders. Some of} the leading blunders to avoid are:

1. Embarrassing or Criticizing the Boss in a Public Forum. One of the oldest traditions in human relations is to "praise in public and criticize in private"

2. Surprising the Boss: Pleasant surprises are expected and appreciated while negative ones are condemned and not appreciated.

3. Bypassing the Boss - Protocol is highly valued in a hierarchical organization. Going around the boss to resolve problems every time is dangerous. However, the career could be damaged and resources limited if a subordinate can accomplish the bypass.

4. Declining an offer of Top Management - Turning down top management more than twice is a serious political blunder. The subordinates have to balance their blunder of refusing requests from powerful someone in the organization. Today, an increasing number of potential managers and professionals decline opportunities for promotion when the new job requires geographic relocation.

\section{Unethical Political Strategies and Tactics}

Any strategy of gaining power can be unethical if practiced in the extreme and with negative intentions. Some of them include:

\subsection{Back Stabbing}

This requires that one pretends to be nice, but all the while plan someone's demise. A frequent form of back stabbing is to initiate a conversation with a rival about the weakness of a common boss, thus encouraging negative comments and making careful mental notes of what the person says. When these comments are passed along to the boss, the rival appears disloyal and foolish

\subsection{Purge all but Loyalists}

The ancient strategy of purge those you have conquered suggests that you remove from the organization rivals who suffered past hurts through your efforts. However, the wounded rivals might retaliate at a vulnerable moment

\subsection{Set a Person Up for Failure}

To set up is to place a person in a position where she or he will either fail out rightly or look ineffective. 


\subsection{Exert Undue Pressure}

It is unethical if used to further leaders' interests at the expense of others. It may have long term repercussions.

\subsection{Divide and Conquer}

The objective is to have peers struggle among themselves, therefore yielding the balance of power to another person. One way of getting subordinates to fight with one another is to place them in intense competition for resources.

\subsection{Play Territorial Games/ Turf wars:}

These involve protecting and boarding resources that give one power, such as information, relationship and decision making authority. Examples of territorial games include relationship hoarding, blocking a high performer from getting promotion or transfer, monopolizing time with important stakeholders, scheduling meetings at odd time for someone not to attend, shutting out co staff from joining the leader on an important assignment.

\section{Exercising Control over Dysfunctional Politics}

Organizational politics is necessary and inevitable, but it can hurt an organization and its members when carried to excess. Excessive politicking can result in lower morale, higher turnover and wasted time and effort, thus, lowering performance. To avoid these negative consequences, leaders according Mitchell (2005) should combat political behavior when it is excessive and dysfunctional in the following ways:

- To control politics, organizational leaders must be aware of its causes and techniques. For instance, during downsizing, the CEO should be on the alert for instances of back stabbing and genuine and transparent attempts to please him/her.

- Open Communication could also constrain the negative impact of political behavior. Open communication helps everyone to know the basis for allocating resources thus reducing the amount of political behavior. Open communication also makes more difficult for some people to control information and pass along gossip as a political weapon.

- Avoiding Favoritism is a string way of minimizing politics within a group, if group members belief that getting the boss to like men is much less important than good job performance in obtaining rewards, they will try to impress him/ her through task - related activities.

- Setting good examples of the top management level reduces the frequency and intensity of organizational politics. When leaders are non-political in their actions, they demonstrate in subtle ways that political behavior is not welcome. It may be helpful for the organizational leader to announce in a staff meeting that devious political behavior is undesirable unprofessional, unethical, unacceptable and is not tolerated

- Goal congruence: Every member of the organization shares the same goals, with thorough understanding of what they mean. If politics will interfere with the organization and individuals achieving their goals, staffs with goal congruence are less likely to play office politics excessively.

- Politics can also be constrained by a threat to discuss questionable information in public forum. People with devious politics usually operate secretly and privately. They are always willing to drop hints and innuendoes and make direct derogatory comments about someone else, provided they will not be identified as the source. An effective way to stop this is to offer to discuss the topic publicly.

\section{Features of Organizational Politics}

Politics is an intentional act of influencing others through the acquired power to enhance self - interest and organizational advancement in the following ways:

- Power characterizes political action.

- Political action takes place when an actor recognizes that achievement of his goals is influenced by the behavior of others.

- Politicking involves the elimination of adversaries by the influential maneuvers of members of the organization.

- Politics involves the management of influence to obtain ends not sanctioned by the formal organization. 
- Any behavior by organizational member that is self - serving may be termed political

- Organizational politics exists wherever people work together.

- behavior referred to as politics takes place in varying degrees in all organizations.

- Not all behaviors are categorized as being 'political'. Asking for an annual increase or salary review is not political but coming together under an umbrella of trade union is a political act.

\section{Tactics of the Organizational Politics}

Organizational political tactics can be categorized into:

a. The organization itself and

b. The individual employees/managers' political tactics

\section{Some Mistakes in Organizational Politics}

\subsection{Failure to plan properly}

It is a common thing to find an organization continuing with a traditional structure long after its objective, plans and external environment have changed. However, organizational structure must be modified to take people into account and to take full advantage of employee strengths and weaknesses. There could be a danger in that different people would deserve to do the same things resulting in conflict or multiple commands. Also, people have a way of coming and going in an organization through retirement, resignation, promotion or death which might make organizing around them risky and their positions, when vacated, hard to describe accurately and to fill adequately.

\subsection{Failure to Clarify Relationships}

This accounts for frictions, politics and inefficiency. Since both the authority and the responsibility for acting are critical, lack of clarity about them is tantamount to lack of knowledge of the parts that members are to play on an organizational team.

\subsection{Failure to Delegate Authority}

The decision - making bottlenecks, excessive referral of small problems to upper echelons, overburdening of top level managers with detail, continual "fire - fighting" and "meeting of crises" and underdevelopment of managers in the lower level of organization give evidence that failing to delegate authority to the proper extent is a mistake which can lead to the followings among others.

\subsection{Failure of Balance of Delegation}

Some managers because of their zeal for decentralization may tend to push decision making too far down in the organization and a system of independent organizational satellites may develop when it is not taken to the extreme, excessive delegation may cause organizational failures.

\subsection{Confusing Lines of Authority with Lines of Information}

The problems and costs of levels of organization and depart mentation could be reduced by opening wide the channels of information. The relevant information should be widely available to people at all levels of the organization. Information gathering should be separated from decision making, since the later requires managerial authority.

\subsection{Granting Authority without Extracting Responsibility}

A notable cause of mismanagement is assignment of authority without holding a person responsible. Authority delegation is not the same thing with responsibility delegation. Super ordinates remain responsible for the proper exercise of authority by their subordinates. 


\subsection{Holding People Who Do Not Have Authority Responsible}

Sometimes managers hold their subordinate responsible for results they have no power to accomplish. This doesn't happen so frequently where organization lines and duties have been clearly set forth, but where a structure of roles is unclear, confused or it does not exist.

\subsection{Careless Application of the staff Device}

There is the obvious danger when top managers surround themselves with staff specialists and become so preoccupied with the specialists' work they exclude from their schedule, the time and attention needed for their line subordinates. The very quality that makes staff specialists valuable (specialized knowledge) also makes them impatient of command. If they were to exercise authority without clear delegation, they would not only undermine the authority of the responsible line official but also breaking down the unity of command.

\subsection{Misuse of Functional Authority}

Problems may also arise from undefined and unrestricted delegation of functional authority. This is could be as a result of the complexities of a modern enterprise often creating instances where it is desirable to give a predominantly staff or service department functional authority over activities in other parts of the organization. The personnel department for example could hire workers for line departments on the basis of psychological or personality test results without consulting with the managers of the line department.

\subsection{Multiple Subordination}

In any organization the controller via accountant prescribes accounting procedures, the purchasing directors prescribes how and where purchases are made, the personnel manager dictates in line with the union contractor, government regulations, how employees shall be classified for pay purposes, vacation schedule and number of hours to be worked. The traffic manager controls the routine of all freights. The public relation director requires that all public utterances of managers and other employees be cleared or meet a prescribed policy line. With these, operating managers find themselves subject to the direction of a number of people with functional authority in addition to their principal superiors who have the final decision over their pay scales and chances for promotion. It is not surprising that many managers where there are so many functional authorities feel frustrated especially those at lower levels.

\subsection{Misunderstanding of the Function of Service Departments}

Sometimes people regard a service department as relatively unnecessary and unimportant and therefore something to be ignored when possible. Contrarily also, many service departments mistakenly look upon their functions, as an end unto itself rather than a service to other departments. For example, a statistics department may forget that it exists to finish data desired by others rather than to produce reports of own choosing. This is the same with personnel department or purchasing department'. The greatest misuse of service department is summoned up in the words "efficient inefficiency" when service departments look more to cost savings than to the efficiency of the entire organization.

\subsection{Over Organization and Under-organization}

Over-organization results from failure to put into practice the idea that the structure of the enterprise is merely a system for making possible the efficient performance of people. Managers tend to complicate the structure by creating many levels and ignore the fact that efficiency is a function of managerial supervision. Managers also over organize by appointing unnecessary line assistances or deputy managers at different levels. Excessive procedures are confused with over-organization. Much of the red tape often blamed on over-organization which really results from poor planning. Too many committees, sapping the time and energies of managers and their staffs are often blamed on over-organization rather than on poor organization. Excessive use of committees often results from having authority delegated to too many positions or form vague delegation which actually points to under-organization. 


\section{Conclusion}

The search requires charting the main lines of organization, considering the organizational philosophy and sketching out consequent authority relationships. Principles of organizing have general application, but the background of each company's operations and needs must be considered in applying these principles. If available personnel do not fit into the idea structure and cannot or should not be pushed aside, the only choice is to modify the structure to fit individual capabilities, attitudes or limitations. Thus, planning will reduce compromising the necessity for principle whenever changes occur in personnel. Planning the organization structure helps determine future personnel needs and required training programmes. It also helps to disclose weakness. Politics is very crucial behavioral process in all organizational setting. According to Ejiogu (1995) an important social influence process with the potential of being either functional or dysfunctional to organizations and their members, depending on how it is played. Effective managers need to be fully aware of the existence of political tactics and should learn how best to manage organizational politics. Power and politics could be used for either good or bad, but those who use them must have a moral obligation to use it responsibly well. Good organizational managers should have the wisdom, knowledge and skill to use them well.

\section{References}

Adeyemo, B, Folajin, T, Sotande, W and Adekunle, A. (2011). Essentials of educational Management. Abeokuta: Goad educational publishers.

Ajayi, O.A. (2009). Basic concepts of administration, planning and economics of education. Ibadan: Gabesther publishers.

Chike-Okoli, A. (2009).A handbook on supervision of instruction. Gabesther publishers

Ladipo, P.K. A and Omoyele, S.O (2005) Management: Theory and Practice. Ilorin BT \& Associates.

Ejiogu A.M (2005). Organizational Politics. In Ejiogu A. Achumba, I and Asika, N (Eds.) Readings in organizational behavior in Nigeria (pp.234 - 239). Lagos: Malthouse Press Limited.

Kinicki, A. (2008). Organizational Politics. Retrieved online on February 6, 2014

Mitchell, R. (2005) Introduction to organizational politics. Retrieved online on February 6, 2014

Ojo, L.B. (2012).Educational administration: Theory and practice. Lagos: Bluesign publication Ltd.

Owolabi, S.O (2007). Political and Cultural Context of Educational Planning. Ibadan: Aderibigbe Publishers.

Szilagyi, A.D and Wallace, M.J. (2008). Organizational Behavior and Performance. London: Scott, Foreman and Company.

Weihrich, Hand Koontz, H. (2003). Management: A global perspective. New York: McGraw - Hill, Inc. 